IRA-International Journal of Education \& Multidisciplinary Studies

ISSN 2455-2526; Vol.06, Issue 02 (2017)

Pg. no. 191-194

Institute of Research Advances

https://research-advances.org/index.php/IJEMS

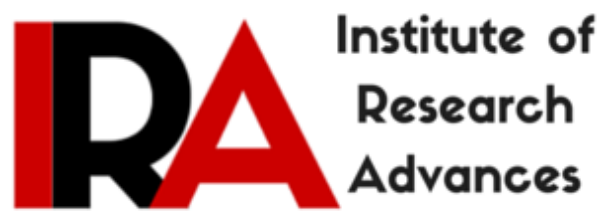

\title{
Analysis of Referral Pattern in Burns to a Tertiary Burn Care Centre in India
}

Dr. J. J. Lankaram M.S., D.N.B., M.Ch.

Assistant Professor, Department of Burns Plastic \& Reconstructive Surgery, Govt. Kilpauk Medical College Hospital, Chennai, India.

Dr. Angeline Selvaraj M.S.,M.Ch.

Associate Professor, Department of Burns, Plastic \& Reconstructive Surgery, Govt.

Kilpauk Medical College Hospital, Chennai, India.

Type of Review: Peer Reviewed.

DOI: http://dx.doi.org/10.21013/jems.v6.n2.p6

\section{How to cite this paper:}

Lankaram, J., \& Selvaraj, A. (2017). Analysis of Referral Pattern in Burns to a Tertiary Burn Care Centre in India. IRA International Journal of Education and Multidisciplinary Studies (ISSN 2455-2526), 6(2), 191-194. doi:http://dx.doi.org/10.21013/jems.v6.n2.p6

(C) Institute of Research Advances

(cc) EY-NC

This work is licensed under a Creative Commons Attribution-Non Commercial 4.0 International License subject to proper citation to the publication source of the work.

Disclaimer: The scholarly papers as reviewed and published by the Institute of Research Advances (IRA) are the views and opinions of their respective authors and are not the views or opinions of the IRA. The IRA disclaims of any harm or loss caused due to the published content to any party. 


\section{Introduction}

Government Kilpauk Medical College Hospital in Chennai has a tertiary burn care centre with an exclusive new building catering to the needs of burn victims. This burn unit was started by PadmashreeDr.Mathangi Ramakrishnan in the year 1981. All types of burns in all age groups are treated here. Management of a burn patient involves multimodal approach and involves the contribution of various specialists. These patients require multiple stages of medical and surgical managements thus prolonging the duration of hospital stay. Though the treatment to the patient is provided free in the government hospital, the relatives or care takers have to spend money for their food and daily needs. Most patients come from lower socioeconomic background and depend on their daily wages for survival making the problem more complex. Burn survivors are scarred and have some physical disability which persists, creating a sense of depression or loss. Major burn victims have a high mortality even in specialized units. Thus ultimately most of the victims and their care givers are not satisfied in the end ${ }^{(2)}$

Key words: Burn Referrals, Tertiary Burn Care Centre, Burn Surface Area (BSA).

\section{Aim}

This is a retrospective study of data to analyze the number of patients who are admitted in the tertiary burn care centre, the BSA affected, place from where they are referred, the time delay and the final outcome.

\section{Materials and methods}

All inpatients admitted in the burn care unit who had initial treatment outside were included. This was a retrospective study of records of the department. Period of study was from First January to Thirty First December of 2015.

\section{Observations}

Out of the 1906 admissions 616 patients were referred from elsewhere. 32\% of admissions were referred admissions. There were 214 male 291 females and 66 and 45 male and female children respectively. When the referral hospitals were analyzed, Chengalpet Medical College Hospital topped the list with 79 patients. 54 patients were sent from Vellore,52 from Thiruvannamalai,36 from Kancheepuram and 16 from Villupuram Medical College Hospital.19 patients were referred from other state hospitals. There were referrals from district head quarters hospitals, hospitals attached to medical colleges and government hospitals within the city also. The BSA \% involved in less than 10\%area was noted in 67 patients and 214 in 10- $40 \% .137$ patients with $41-60 \%$ BSA were referred while more than 61\% BSA were 198. Studying the outcome showed that, all burn patients who were referred with less than $10 \%$ BSA were discharged and more than $80 \%$ BSA expired in the hospital. The mortality in 10 to $40 \%$ BSA group was 61 and discharges were153, which included 16 discharges done against medical advise.41-60\% BSA burn group, had 105 deaths and 30 discharges of which 14 were against medical advice. More than 61\% BSA group had194 deaths and 4 discharges, of which only one patient in $61-80 \%$ was discharged after complete burn management and 4 patients were discharged against medical advice.

Analysis of the period of referral showed that majority, 410 patients were sent on the first post burn day itself and 136 on the second post burn day. Though there was a dramatic reduction of referrals after second day of burns there was a rise in the 6-10 post burn day group ( 23 patients). When the patients referred on first post burn day were analyzed, out of the 410 admitted 270 patients died and 140 were discharged and more than $80 \%$ BSA burn victims were 90 . The teaching medical college hospitals too had referred 49 patients within 24 hours of burns.Out of the 136 patients referred on the second post burn day 61 survived and 75 died. This group had 18 patients with more than $80 \%$ BSA and 14 of them were from teaching institutions. 
Percentage of referrals

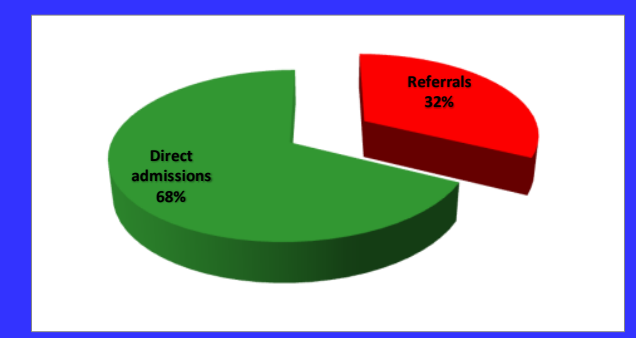

Other referrals

Timing of referral
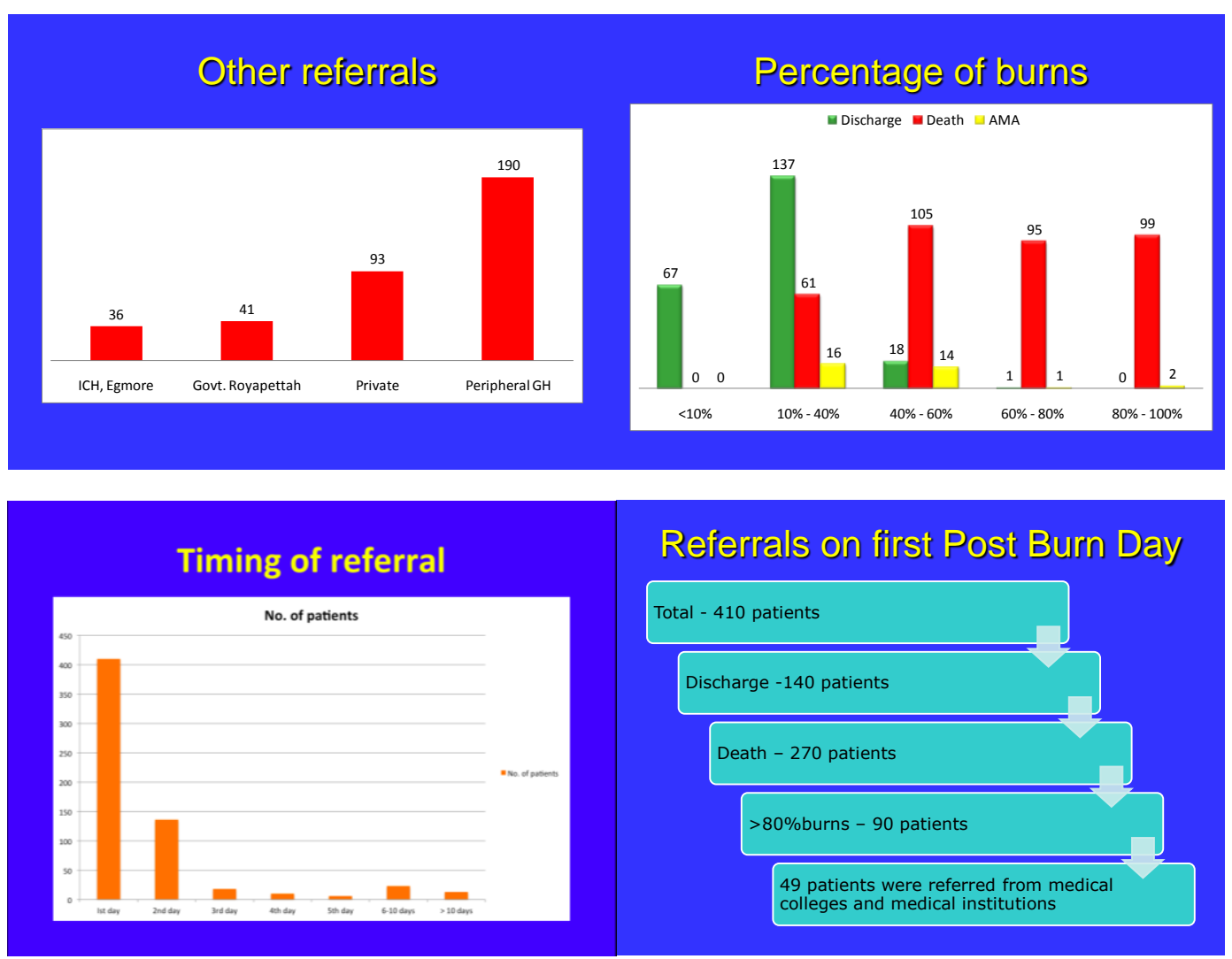

Number of burn victims - Cities

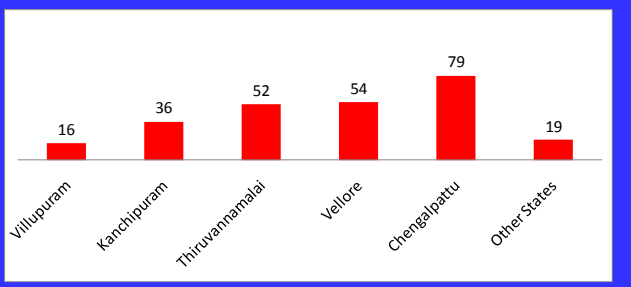

Referrals on second Post Burn Day

OUTCOME IN REFERRAL CASES
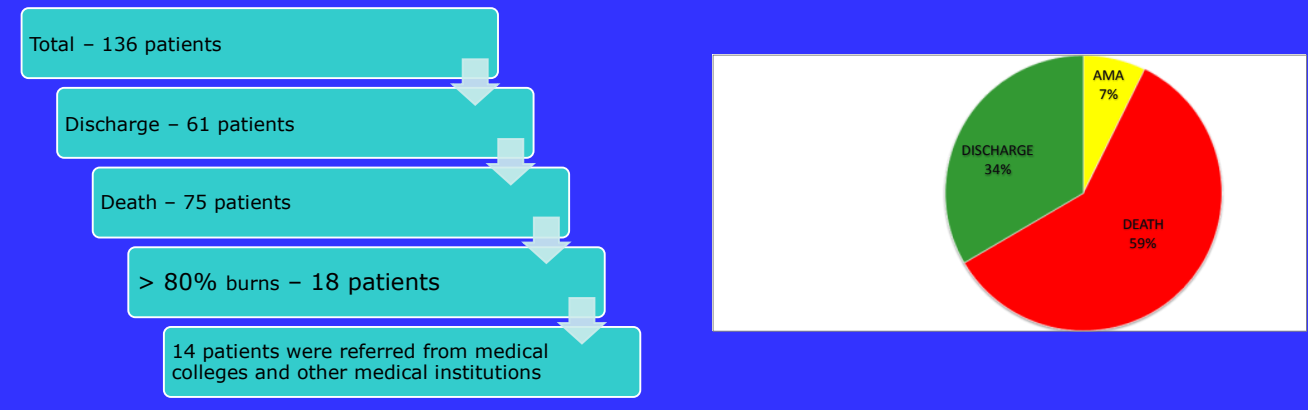


\section{Discussion}

Burn care is stressful as it involves 24 hour care of the patients and the immediate post burn emotional outburst among friends and family. Being medico-legal cases, documentations are elaborate and the need for interaction with the police and judiciary is mandatory. The distribution of age group affected varies from pediatric to geriatric group and the intense change in the physiology of body functions creates a lot of biochemical changes forcing a team approach for 'wholistic' burn care. This puts a lot of other supportive departments into work. The plethora of flame burn, scald, electrical burn, chemical burn and cracker blast injuries need multiple emergency and elective surgical procedures ${ }^{(6)}$. The duration of hospital stay differs with the depth of burn and the amount of area affected ${ }^{(5)}$. Thus making a lot of man hour loss of productivity not only to the patient but also to the care giver and increase in the financial strain on the victims family.

\section{Conclusions}

The knowledge of burn care can be used judicially by the initial doctor attending on these victims, as most of the teaching institutions are provided with qualified plastic surgeons and facilities to do the initial burn resuscitation. Burns with less than $10 \%$ BSA and more than $80 \%$ BSA need not be sent to tertiary care centre as the outcome is the same ${ }^{(1)}$. Proper training in burn care can be given to all students in the peripheral medical colleges and this will reduce the financial loss and mental agony of the family and also help in improving the quality of work and outcome in tertiary burn care centre due to reduction in volume of patient load ${ }^{(3) \text {. }}$

\section{Referances}

1. ACI Statewide Burn Injury Service NSW Burn transfer guidelines.

2. American Burn Association, guidelines(pp79-86)Resources for optimal care of the injured patient 2006, committee on trauma, American college of surgeons.

3. J. Burn CareRes.2010 Jan-Feb,31(1)26-30.

4. Journal of burn care and Rehabilitation ,1990,11;98-104.

5. Referral criteria for specialised burn service 2016 guidance for burns referral- including contact details.

6. University of Winconstin Hospital and clinics, level 1 winter2008. 